\title{
Neuropathic pain: a principal component of pain that should not be neglected in ankylosing spondylitis
}

\author{
Ling zhou \\ Shanghai Changzheng Hospital \\ ting li \\ Shanghai Changzheng Hospital \\ xin wu \\ Shanghai Changzheng Hospital \\ Hongjuan Lu \\ shanghai changzheng hospital \\ Li Lin \\ Shanghai Changzheng Hospital \\ Lingying Ye \\ Shanghai Changzheng Hospital \\ jian yin \\ Shanghai Changzheng Hospital \\ juan zhao \\ Shanghai Changzheng Hospital \\ xiuwen wang \\ Shanghai Changzheng Hospital \\ jianye bian \\ Shanghai Changzheng Hospital \\ Huji Xu ( $\square$ xuhuji@smmu.edu.cn ) \\ Changzheng Hospital
}

\section{Research article}

Keywords: Neuropathic pain, ankylosing spondylitis, neurotransmitters

Posted Date: January 25th, 2021

DOI: https://doi.org/10.21203/rs.3.rs-153298/v1

License: (c) (i) This work is licensed under a Creative Commons Attribution 4.0 International License. Read Full License 


\section{Abstract \\ Background}

Pain in AS is currently considered an inflammatory pain (IP). However, it was found that some patients still had the sensation of pain even without inflammation. Our study was to investigate whether ankylosing spondylitis (AS) pain has a neuropathic pain (NeP) component.

\section{Methods}

The study consisted of three parts. The first included 182 AS patients to assess neuropathic pain in AS patients. The second included63 patients to evaluate pain improvement after etanercept therapy. The third included 20 AS patients and 10 healthy controls (HCs) to detect serum neurotransmitters.

\section{Results}

We found out that 55 paitents (30.21\%) had possible NeP, and 14 (7.70\%) had definite NeP. There were significant differences between the groups with respect to nocturnal pain (NP), peripheral pain (PP), total back pain (TBP), BASDAl, ASDAS-CRP, HAD-A, HAD-D and BASDAl-fatigue but not CRP concentrations. Principal component analysis (PCA) of AS pain revealed that the weight of NeP was greater than PP in the first principal component (0.703 vs 0.639). Structural equation modelling (SEM) revealed that NeP altered disease activity $(\beta=0.62, P<0.001)$, which influenced psychological status $(\beta=0.42, P<0.001)$. Of 63 patients who used etanercept for 3 months, significant improvement was found in NP, TBP and PP (all $P<0.0001)$ but not in PDQ $(10.60 \pm 6.85$ vs $9.98 \pm 6.40, P=0.067)$. Serum norepinephrine concentrations in patients with positive PDQ were greater than those in patients with negative PDQ and $\mathrm{HC}$.

\section{Conclusions}

We conclude that NeP contributes to pain in AS patients.

\section{Background}

Ankylosing spondylitis (AS) is an autoinflammatory disease whose aetiology remains to be established. It mainly involves the axial skeleton and is characterized by sacroiliac arthritis and enthesitis with pain, stiffness and joint deformity as the main symptoms[1].Pain in AS is currently considered an inflammatory pain (IP). However, pain in AS is not always correlated with the inflammatory indexes of the disease, such as Creactive protein (CRP) concentrations or the erythrocyte sedimentation rate (ESR). Biologics are the most effective treatment for AS at present. It was reportedthat the serological parameters and radiological outcomes were improved in approximately $60 \%$ of $A S$ patients who received tumour necrosis factor (TNF) inhibitors[2].However, it was found in clinical practice that some patients still had the sensation of pain even though the inflammatory indexes had resolved normally after administration of the biologics. In 2017, Bidad et al.found that AS-associated pain was not merely a kind of IP but also involved neuropathic pain (NeP)[3].

Currently, there are no large-scale clinical trials distinguishing IP from NeP. Given the large population and economic condition of most AS patients in China, it is extremely important to find an accurate and convenient tool for differentiating between IP and NeP. The painDETECT Questionnaire (PDQ) has proven to be a simple and reliable tool that screens for NeP;it consists of 9 simple self-assessment questions suitable for patient selfscoring and large-scale epidemiological investigation[4].The aims of our research were to comprehensively assess the clinical symptoms of AS pain by making use of the PDQ as part of the NeP assessment in combination with NP, TBP, PP, AS activity, anxiety, depression and fatigue.

\section{Methods}

1. Part one: This part of the study included 182 patients who were confirmed in our Department of Rheumatology \& Immunology to have AS. AS was diagnosedfollowing the 1984 Modified New York Criteria for Ankylosing Spondylitis[5].The general data collected for these patients included age, gender and the extent of AS. The Bath Ankylosing Spondylitis Disease Activity Index(BASDAI)[6],the CRP-based Ankylosing Spondylitis Disease Activity Score(ASDAS-CRP)[7],the BASDAI-Fatigue score[8],and the PDQ[4] were used, and anxiety and depression levels were determined using the Hospital Anxiety and Depression Scale (HADS) [9]. NP and BP were assessed by a visual analogue scale (VAS). PP was assessed by Q3 of BASDAl.

2. Part two: This part of the study included 63 AS patients ( 31 with $P D Q>12$ and 32 with $P D Q \leq 12$ ) who were given a subcutaneous injection of $25 \mathrm{mg}$ etanercept for 12 weeks. Before drug administration, all patients underwent strict screening tests for tuberculosis, hepatitis and tumours. The main clinical parameters included age, gender, ASDAS-CRP, BASDAI-Fatigue, PDQ and HAD, which were recorded before and after drug administration. 
3. Part three: This part of the study involved 20AS patients ( 6 with PDQ $>19$ and 14 with PDQ $\leq 12$ ). Ten age- and gender-matched healthy individuals were used as the controls. Serum neurotransmitter concentrations, including norepinephrine (NE), 5-hydroxytryptamine (5HT), glycine (Gly), glutamic acid (Glu), y-aminobutyric acid (GABA), 5-hydroxyindoleacetic acid (5HIAA), kynurenine (KYN), and tryptophan (TRP), were measured. Differences in the concentrations of these neurotransmitters were compared among the three groups. All blood samples were sent to Anpel Laboratory Technologies (Shanghai, China) for testing.

4. PDQ calculation: The PDQ included 9 simple self-assessment questions with no need for physical examination and therefore was suitable for self-assessment and large-scale epidemiological investigation. Of the 9 questions, 7 were weighted sensory items scored by a 0 - 5 scoring system to indicate no manifestation to a severe degree, and the other 2 were related to radiating pain and the mode of pain onset. The total score of the nine items indicated the following: $\leq 12$, a low possibility of NeP; $13-18$, the existence of mixed pain; and $\geq 19$, the possible presence of NeP.

HADS score: Anxiety and depression were evaluated usingthe HADS. Briefly, a score of 0-7 indicated no anxiety or depression, 8-10 indicated possible anxiety or depression, and 11-21 indicated a high probability of both conditions.

\section{Statistical analysis}

Statistical analyses were conducted using SPSS software (ver. 16.0). Data that had a normal distribution are presented as the mean \pm SD. Continuous variables that had a normal distribution were evaluated using a two-sample $t$-test. Analysis of variance (ANOVA) was employed to look for multigroup differences, and unordered categorical variables were assessed using the chi-squared test. Principal component analysis (PCA) was performed by dimension reduction processing with SPSS statistical software. SEM was analysed using Amos ver. 23.0.0, and any possible relationships between latent variables were evaluated using SEM.

\section{Results}

1. General clinical information of AS patients

1) Of the 182AS patients who participated in the first phase of the study, 113 (62.08\%) had no NeP (PDQ $\leq 12), 55$ (30.21\%) had possible NeP $(12<\mathrm{PDQ}<19)$, and $14(7.7 \%)$ had definite NeP (PDQ $\geq 19)$.

2) There were significant differences in NP $(2.25 \pm 2.85$ vs $5.34 \pm 4.55 v s 5.87 \pm 3.02, P<0.000)$, TBP $(2.23 \pm 2.62$ vs $5.54 \pm 4.92$ vs $5.85 \pm 2.48, P<0.000)$, and PP (1.25 \pm 1.79 vs $2.44 \pm 2.40$ vs $4.54 \pm 2.54, P<0.000)$ between the three groups (PDQ $\leq 12,12<\mathrm{PDQ}<19$ and PDQ $\geq 19)$. There were differences in BASDAI, ASDAS and psychological status, including anxiety, depression and fatigue, but there was no significant difference in CRP (12.75 \pm 18.12 vs $14.41 \pm 11.79$ vs $16.77 \pm 11.36, P=0.606)$ (Table 1 ).

2. PCA: PCA was employed to determine the first principal component, and the results showed that it accounted for $62.7 \%$ of the population variance. The first principal component was calculated as follows:

$\mathrm{F} 1=0.881 \times(\mathrm{NP})+0.899 \times(\mathrm{TBP})+0.703 \times(\mathrm{NeP})+0.639 \times(\mathrm{PP})$, indicating that the weight of NeP was greater than that of PP in the first principal component ( 0.703 vs 0.639). The common factor (CF) of pain was calculated with a rotated component matrix, indicating that there are three major dimensions of pain in AS patients: CF 1 represents NP and TBP, CF 2 represents peripheral pain, and CF 3 represents NeP. CF analysis showed that NeP was a relatively independent type of AS pain (Table 2).

3. Use of SEM: SEM was used to analyse the impact of NeP on disease activity and psychology. BASDAI and ASDAS-CRP were employed to assess the disease activity index, while HAD-A and HAD-D assessed the psychological indexes of patients. SEM was successfully established, with a probability level of 0.227 , a CMIN/DF ratio of 1.413 , a CFI of 0.996 , an NFI of 0.987 , and an RMSEA of 0.048 . The SEM results showed that PDQ could alter disease activity $(\beta=0.62, P<0.001)$, which in turn affected psychological status $(\beta=0.42, P<0.001)($ Fig. 1).

4. Pain improvement after biological treatment: Of the 63 AS patients who used etanercept for 12 weeks, PDQ was $\leq 12$ in 32 patients, and PDQ was > 12 in the remaining 31 patients. The results suggested that the degrees of NP, TBP and PP were significantly decreased after drug administration, but PDQ was not significantly decreased (10.60 \pm 6.85 vs $9.98 \pm 6.40 P=0.067)$. Subgroup analysis revealed that PDQ was decreased significantly in AS patients with PDQ $>12(17.06 \pm 2.40$ vs $15.55 \pm 3.69, P=0.006)$ and did not show a significant decrease in AS patients with $\mathrm{PDQ} \leq 12(4.34 \pm 2.47$ vs $4.59 \pm 2.79, \mathrm{P}=0.508)$.

5. Detection of neurotransmitters in AS patients: Of the 20 AS patients in the third part of the study, PDQ was > 19 in 6 patients and PDQ $\leq 12$ in 14 patients. The NE concentration in patients with PDQs $>19$ was significantly higher than that in patients with PDQs $\leq 12$ and healthy controls $(0.21$ \pm 0.06 vs $0.13 \pm 0.05$ vs $0.07 \pm 0.02, P<0.001)$. There was no significant difference in other neurotransmitter concentrations.

\section{Discussion}


The primary symptom of AS is pain, which is currently recognized as a type of IP.[10] For this reason, previous research and the development of new anti-AS medications have mainly focused on drugs that can block inflammatory factors[11][12][13].Given the large capacity of outpatients and the short duration of communication between the physician and the patient in the actual clinical situation in China, both the physician and the patient usually focus their attention on laboratory and imaging findings and pay scant attention to pain and other subjective symptoms. However, it is often found that some AS patients complain of pain even when inflammatory indexes such as ESR and CRP are within the normal ranges or after the administration of biologics. In addition, this kind of pain often has the characteristics of NeP:numbness and pricking sensations. It seems too simple and biased to explain the clinical symptoms of AS simply as IP. More studies in recent years have found that pain in AS patients is not always correlated with inflammation[14][15]. Freynhagen et al. investigated more than 8,000 patients with chronic pain and found that approximately one-third of them had pain of a neuropathic nature[16]. Using head MRI, Wu et al. demonstrated NeP in AS patients and found that the corresponding abnormality in the grey matter was correlated with clinical symptoms[17].

In the present study, approximately one-third of 182 AS patients had possible or definite NeP. Borman et al[18].used the Leeds Assessment of Neuropathic Symptoms and Signs (LANSS) and Douleur Neuropathique 4 (DN4) to assess pain in 58 AS patients and found that more than $50 \%$ had NeP. Choi et al.used the PDQ to assess 105 AS patients and reported that 15 (14.2\%) had NeP. All these findings suggest that NeP universally occurs in AS patients[19]. In addition, the PCA of pain in our study showed that the weight of NeP was greater than that of PP. CF analysis showed that pain in AS consists of three dimensions, that is, IP (NP and TBP), NeP and PP, which are relatively independent and represent the three dimensions of AS pain. This finding suggests that NeP is an important component of AS pain. The SEM results suggested that NeP affects the disease activity of AS, which further alters the psychological status of AS patients. Based on the above results, we believe that the incidence of $\mathrm{NeP}$ is relatively high in AS patients and that NeP is an important component of AS pain, which has a tremendous impact on both AS disease activity and the psychological status of AS patients.

Studies on the therapeutic effect of TNF-a on NeP have produced meaningful results. Some studies have reported that local or spinal administration of drugs that antagonize TNF-a activity attenuates pain behaviour in neuropathic animal models[20][21].0ther studiesfound that mechanical allodynia in a rat model of central neuropathic pain, produced by T13 spinal cord hemisection, was attenuated by the immediate intrathecal administration of etanercept 1-4 weeks after injury to the spinal cord[22]. However, to the best of our knowledge, we are unaware of any randomized controlled clinical trials of infliximab or etanercept for the treatment of other forms of NeP. TNF inhibitors are currently the most effective drugs for AS. The results of our study demonstrated that axial pain, PP and various inflammatory indexes were improved significantly in AS patients who were administered etanercept for 12 weeks, but PDQ was not improved significantly, suggesting that TNF inhibitors did not work as effectively as expected. This may be because AS-associated NeP may have other action mechanisms other than the TNF inflammatory pathway. Given this postulation, we detected 8 neurotransmitters in the peripheral blood of 20 AS patients and found that the serum NE concentrations in AS patients with high PDQ were significantly elevated. Both NE and $5 \mathrm{HT}$ are pain-related neurotransmitters that participate in regulating both algesic and analgesic processes. Peripherally, these neurotransmitters are algesic factors that exert their regulatory effect on local neurocytes via second messengers such as calcium ions or cyclic nucleotides or through a paracrine pathway producing pain by the stimulation of sensory nerve endings. Detection of the concentration of algesic factors in peripheral blood can, to some extent, reflect the degree of pain[23].Based on this finding, we are using pregabalin to treat NeP in AS patients, and related data are being collected.

This study has some limitations. We only detected neurotransmitters in the peripheral blood of a limited number of AS patients. We plan to further expand the sample size in our ongoing research and use head MRI to explore the structural or functional changes in the pain-related regions of the central nervous system.

\section{Conclusions}

In summary, $\mathrm{NeP}$ is a common occurrence in AS patients as well as an important component and one of the three dimensions of AS pain. TNF inhibitors do not seem to be as effective as expected in improving AS-associated NeP. The NE concentrations in the peripheral blood of AS patients with NeP complications are significantly elevated, suggesting that interference with neurotransmitter actions may be a promising new approach to the treatment of AS-associated NeP.

\section{Abbreviations}

Ankylosing spondylitis: AS; Neuropathic pain: NeP; inflammatory pain, IP; nocturnal pain:NP; peripheral pain: PP; total back pain: TBP; C-reactive protein: CRP; erythrocyte sedimentation rate: ESR; tumour necrosis factor: TNF; painDETECT Questionnaire: PDQ;The Bath Ankylosing Spondylitis Disease Activity Index: BASDAl; the CRP-based Ankylosing Spondylitis Disease Activity Score: ASDAS-CRP; Hospital Anxiety and Depression Scale: HADS; norepinephrine: NE; 5-hydroxytryptamine: $5 \mathrm{HT}$, glycine: Gly; glutamic acid: Glu; $\gamma$-aminobutyric acid : GABA; 5-hydroxyindoleacetic acid: 5HIAA; kynurenine: KYN; tryptophan:TRP

\section{Declarations}

\section{Ethics approval and consent to participate}


The study was approved by the Research ethics board of Shanghai Changzheng Hospital (2017SL046), with all participants signing informed consent.

\section{Consent for publication}

Not applicable.

Availability of data and material

All relevant data are contained within the paper.

Competing interests

The authors declare that they have no competing interests.

Funding

This study was funded by Shanghai Municipal Key Clinical Specialty (shslczdzk02602).

Authors' contributions

$L Z, T L$, and HX were responsible for study conception and design. HL, XW, JB and LL were responsible for the acquisition of data. LY, JY, and JZ performed the data analysis and interpretation. All authors were involved in drafting the article or revising it critically for important intellectual content, and all authors approved the final version to be published.

\section{Acknowledgements}

Not applicable

\section{References}

1. Zong HX, Xu SQ, Tong H, Wang XR, Pan MJ, Teng YZ: Effect of anti-tumor necrosis factor alpha treatment on radiographic progression in patient with ankylosing spondylitis: A systematic review and meta-analysis. Mod Rheumato/ 2019, 29(3):503-509.

2. Braun J, van der Horst-Bruinsma IE, Huang F, Burgos-Vargas R, Vlahos B, Koenig AS, Freundlich B: Clinical efficacy and safety of etanercept versus sulfasalazine in patients with ankylosing spondylitis: a randomized, double-blind trial. Arthritis Rheum 2011, 63(6):1543-1551.

3. Bidad K, Gracey E, Hemington KS, Mapplebeck JCS, Davis KD, Inman RD: Pain in ankylosing spondylitis: a neuro-immune collaboration. Nat Rev Rheumatol 2017, 13(7):410-420.

4. Freynhagen R, Baron R, Gockel U, Tolle TR: painDETECT: a new screening questionnaire to identify neuropathic components in patients with back pain. Curr Med Res Opin 2006, 22(10):1911-1920.

5. Goie The HS, Steven MM, van der Linden SM, Cats A: Evaluation of diagnostic criteria for ankylosing spondylitis: a comparison of the Rome, New York and modified New York criteria in patients with a positive clinical history screening test for ankylosing spondylitis. Br $J$ Rheumatol 1985, 24(3):242-249.

6. Dernis-Labous E, Messow M, Dougados M: Assessment of fatigue in the management of patients with ankylosing spondylitis. Rheumatology (Oxford) 2003, 42(12):1523-1528.

7. van der Heijde D, Lie E, Kvien TK, Sieper J, Van den Bosch F, Listing J, Braun J, Landewe R, Assessment of SpondyloArthritis international S: ASDAS, a highly discriminatory ASAS-endorsed disease activity score in patients with ankylosing spondylitis. Ann Rheum Dis 2009, 68(12):1811-1818.

8. van Tubergen A, Coenen J, Landewe R, Spoorenberg A, Chorus A, Boonen A, van der Linden S, van der Heijde D: Assessment of fatigue in patients with ankylosing spondylitis: a psychometric analysis. Arthritis Rheum 2002, 47(1):8-16.

9. Zigmond AS, Snaith RP: The hospital anxiety and depression scale. Acta Psychiatr Scand 1983, 67(6):361-370.

10. Lindstrom U, Bremander A, Haglund E, Bergman S, Petersson IF, Jacobsson LT: Back pain and health status in patients with clinically diagnosed ankylosing spondylitis, psoriatic arthritis and other spondyloarthritis: a cross-sectional population-based study. BMC Musculoskelet Disord 2016, 17:106.

11. Mease P, Walsh JA, Baraliakos X, Inman R, de Vlam K, Wei JC, Hunter T, Gallo G, Sandoval D, Zhao F et al: Translating Improvements with Ixekizumab in Clinical Trial Outcomes into Clinical Practice: ASAS40, Pain, Fatigue, and Sleep in Ankylosing Spondylitis. Rheumatol Ther 2019, 6(3):435-450.

12. Deodhar A, Conaghan PG, Kvien TK, Strand V, Sherif B, Porter B, Jugl SM, Gandhi KK, group Ms: Secukinumab provides rapid and persistent relief in pain and fatigue symptoms in patients with ankylosing spondylitis irrespective of baseline C-reactive protein levels or prior tumour 
necrosis factor inhibitor therapy: 2-year data from the MEASURE 2 study. Clin Exp Rheumatol 2019, 37(2):260-269.

13. Benucci M, Damiani A, Li Gobbi F, Grossi V, Infantino M, Manfredi M, Niccoli L, Cantini F: Therapeutic Potential of Ixekizumab in the Treatment of Ankylosing Spondylitis: A Review on the Emerging Clinical Data. Ther Clin Risk Manag 2020, 16:287-297.

14. Li T, Liu Y, Sheng R, Yin J, Wu X, Xu H: Correlation Between Chronic Pain Acceptance and Clinical Variables in Ankylosing Spondylitis and Its Prediction Role for Biologics Treatment. Front Med (Lausanne) 2020, 7:17.

15. Kim TW, Son SM, Lee JS: Neuropathic pain in ankylosing spondylitis: a meta-analysis. Z Rheumato/ 2020, 79(1):95-102.

16. Freynhagen R, Baron R, Tolle T, Stemmler E, Gockel U, Stevens M, Maier C: Screening of neuropathic pain components in patients with chronic back pain associated with nerve root compression: a prospective observational pilot study (MIPORT). Curr Med Res Opin 2006, 22(3):529-537.

17. Wu Q, Inman RD, Davis KD: Neuropathic pain in ankylosing spondylitis: a psychophysics and brain imaging study. Arthritis Rheum 2013, 65(6):1494-1503.

18. Borman P, Kaygisiz F, Yaman A: Neuropathic component of low back pain in patients with ankylosing spondylitis. Mod Rheumato/2020:1-6.

19. Choi JH, Lee SH, Kim HR, Lee KA: Association of neuropathic-like pain characteristics with clinical and radiographic features in patients with ankylosing spondylitis. Clin Rheumatol 2018, 37(11):3077-3086.

20. Svensson $\mathrm{Cl}$, Schafers M, Jones TL, Powell H, Sorkin LS: Spinal blockade of TNF blocks spinal nerve ligation-induced increases in spinal Pp38. Neurosci Lett 2005, 379(3):209-213.

21. Andrade P, Hoogland G, Del Rosario JS, Steinbusch HW, Visser-Vandewalle V, Daemen MA: Tumor necrosis factor-alpha inhibitors alleviation of experimentally induced neuropathic pain is associated with modulation of TNF receptor expression. J Neurosci Res 2014, 92(11):1490-1498.

22. Marchand F, Tsantoulas C, Singh D, Grist J, Clark AK, Bradbury EJ, McMahon SB: Effects of Etanercept and Minocycline in a rat model of spinal cord injury. Eur J Pain 2009, 13(7):673-681.

23. Ban EG, Brassai A, Vizi ES: The role of the endogenous neurotransmitters associated with neuropathic pain and in the opioid crisis: The innate pain-relieving system. Brain Res Bull 2020, 155:129-136.

\section{Tables}

Table 1. Clinical data of AS patients in different groups

\begin{tabular}{|c|c|c|c|c|}
\hline & $\begin{array}{l}\mathrm{PDQ} \leq 12 \\
(n=113)\end{array}$ & $\begin{array}{l}12<\mathrm{PDQ}<19 \\
(n=55)\end{array}$ & $\begin{array}{l}\mathrm{PDQ} \geq 19 \\
(n=14)\end{array}$ & $P$-value \\
\hline $\operatorname{Sex}(M / F)$ & $102 / 11$ & $53 / 2$ & $8 / 6$ & 0.687 \\
\hline Age (years) & $36.96 \pm 11.60$ & $36.36 \pm 8.88$ & $37.43 \pm 10.78$ & 0.923 \\
\hline Nocturnal pain & $2.25 \pm 2.85$ & $5.34 \pm 4.55$ & $5.87 \pm 3.02$ & $\bowtie 0.000 * \star *$ \\
\hline LBP & $2.23 \pm 2.62$ & $5.54 \pm 4.92$ & $5.85 \pm 2.48$ & $\nabla 0.000 * \star \star$ \\
\hline Peripheral pain & $1.25 \pm 1.79$ & $2.44 \pm 2.40$ & $4.54 \pm 2.54$ & $\llbracket 0.000 * \star *$ \\
\hline CRP & $12.75 \pm 18.12$ & $14.41 \pm 11.79$ & $16.77 \pm 11.36$ & 0.606 \\
\hline ASDAS-CRP & $1.29 \pm 0.76$ & $2.09 \pm 0.70$ & $2.60 \pm 0.81$ & $\bowtie 0.000 * \star \star$ \\
\hline BASDAI & $1.71 \pm 1.56$ & $3.72 \pm 1.88$ & $5.16 \pm 1.95$ & $\nabla 0.000 * \star \star$ \\
\hline HAQ & $4.39 \pm 5.01$ & $8.0 \pm 10.65$ & $8.96 \pm 9.49$ & $0.026^{*}$ \\
\hline HAD-An & $4.46 \pm 3.30$ & $6.23 \pm 3.21$ & $7.50 \pm 2.47$ & $0.000 * \star \star$ \\
\hline HAD-De & $5.48 \pm 3.81$ & $6.63 \pm 3.30$ & $9.00 \pm 3.32$ & $0.002^{*}$ \\
\hline BASDAl-fatigue & $2.58 \pm 2.40$ & $3.87 \pm 2.39$ & $5.67 \pm 2.31$ & $\nabla 0.000 * * *$ \\
\hline
\end{tabular}

PDQ=PainDetection Questionnaire; LBP=Low back pain; CRP=C-reactive protein; ASDAS-CRP=Ankylosing Spondylitis disease activity score-CRP; BASDAl=Bath assessment of ankylosing spondylitis disease activity index; HAQ=Health assessment questionnaire; HAD-An=Hospital Anxiety and Depression Scale-Anxiety; HAD-D=Hospital Anxiety and Depression Scale-Depression

Data are expressed as the mean \pm standard deviation (SD), $P$-value comparison between the three groups, ${ }^{\star \star \star} P<0.000$,

$\star \star \star P<0.001, * * P<0.01, * P<0.05$

Table 2. Principal component analysis 
Table 2a.Component matrix ${ }^{a}$

\begin{tabular}{|lllll|}
\hline & C1 & C 2 & C3 & C 4 \\
\hline PDQ & 0.703 & 0.422 & -0.572 & 0.001 \\
\hline Nocturnal pain & 0.881 & -0.411 & 0.045 & 0.229 \\
\hline LBP & 0.899 & -0.361 & 0.070 & -0.236 \\
\hline Peripheral pain & 0.639 & 0.610 & 0.468 & 0.014 \\
\hline
\end{tabular}

Method of extraction: Principal Component Analysis ${ }^{\text {a }}$

a. Four components wereextracted.

Note: $\mathrm{C}=$ component; LBP = low back pain

Table 2b.Rotated Component Matrix ${ }^{\text {a }}$

\begin{tabular}{|lcccc|}
\hline & C 1 & C 2 & C 3 & C4 \\
\hline PDQ & .224 & .213 & .951 & .006 \\
\hline Nocturnalpain & .949 & .139 & .201 & -.211 \\
\hline LBP & .928 & .185 & .201 & .255 \\
\hline Peripheralpain & .176 & .963 & .205 & .006 \\
\hline
\end{tabular}

Method of extraction: Principal Component Analysis

Method of rotation: Caesar normal maximum variance method a

a. Rotation converged in 5 iterations

Note: $P<0.01$ by Bartlett's test; the results of first principal component calculation wereas follows:

$\mathrm{F} 1=0.881 \times($ nocturnal pain $)+0.899 \times($ axial pain $)+0.703 \times($ neneuropathic pain $)+0.639 \times($ peripheral pain $)$.

The weight ofneuropathic pain wasgreater than peripheral pain in the first principal component (0.703vs 0.639). Common factors (CF) of pain calculated by rotated component matrix analysis: CF 1 represents nocturnal pain and low back pain; CF 2 represents peripheral pain; and CF 3 represents PDQ.

$\mathrm{PDQ}=$ PainDetection Questionnaire

Table 3. Changes in the clinical data in 63 patients who were given tanercept for 6 months 


\begin{tabular}{|c|c|c|c|c|c|c|c|c|c|}
\hline \multicolumn{3}{|c|}{$P D Q \leq 12(n=32)$} & \multirow[b]{2}{*}{ P-value } & \multicolumn{3}{|c|}{$P D Q>12(n=31)$} & \multicolumn{3}{|l|}{ Overall } \\
\hline & $\begin{array}{l}\text { Baseline } \\
\text { phase }\end{array}$ & $\begin{array}{l}\text { After drug } \\
\text { administration }\end{array}$ & & $\begin{array}{l}\text { Baseline } \\
\text { phase }\end{array}$ & $\begin{array}{l}\text { After drug } \\
\text { administration }\end{array}$ & P-value & $\begin{array}{l}\text { Baseline } \\
\text { phase }\end{array}$ & $\begin{array}{l}\text { After drug } \\
\text { administration }\end{array}$ & P-value \\
\hline PDQ & $\begin{array}{l}4.34 \pm \\
2.47\end{array}$ & $4.59 \pm 2.79$ & 0.5076 & $\begin{array}{l}17.06 \pm \\
2.40\end{array}$ & $15.55 \pm 3.69$ & $0.0059 * *$ & $\begin{array}{l}10.60 \pm \\
6.85\end{array}$ & $9.98 \pm 6.40$ & 0.0671 \\
\hline $\begin{array}{l}\text { Nocturnal } \\
\text { pain }\end{array}$ & $\begin{array}{l}2.85 \pm \\
3.41\end{array}$ & $1.63 \pm 1.88$ & $0.0044^{\star *}$ & $\begin{array}{l}6.61 \pm \\
5.20\end{array}$ & $3.42 \pm 2.30$ & $\hat{0}_{0.0001 * \star \star \star}$ & $\begin{array}{l}4.70 \pm \\
4.75\end{array}$ & $2.49 \pm 2.26$ & $\begin{array}{l}< \\
0.0001^{\star \star \star \star}\end{array}$ \\
\hline LBP & $\begin{array}{l}2.62 \pm \\
3.11\end{array}$ & $1.73 \pm 1.85$ & $0.0120^{*}$ & $\begin{array}{l}7.01 \pm \\
3.32\end{array}$ & $3.32 \pm 2.30$ & $\begin{array}{l}<.0001 * \star \star \star\end{array}$ & $\begin{array}{l}4.78 \pm \\
5.04\end{array}$ & $2.50 \pm 2.21$ & $<.0001^{\star * * * \star}$ \\
\hline $\begin{array}{l}\text { Peripheral } \\
\text { pain }\end{array}$ & $\begin{array}{l}1.55 \pm \\
2.28\end{array}$ & $1.25 \pm 1.95$ & 0.2161 & $\begin{array}{l}3.23 \pm \\
2.63\end{array}$ & $1.72 \pm 2.40$ & $<.0001^{\star \star \star \star *}$ & $\begin{array}{l}2.38 \pm \\
2.58\end{array}$ & $1.48 \pm 1.99$ & $\begin{array}{l}< \\
0.0001 * \star \star \star\end{array}$ \\
\hline CRP & $\begin{array}{l}12.92 \pm \\
17.23\end{array}$ & $7.40 \pm 11.47$ & 0.0017 ** & $\begin{array}{l}14.98 \pm \\
10.88\end{array}$ & $6.41 \pm 3.91$ & $\hat{0}_{0.0001^{\star * \star *}}$ & $\begin{array}{l}13.93 \pm \\
14.38\end{array}$ & $6.91 \pm 8.56$ & $<.0001^{\star * * * \star}$ \\
\hline BASDAI & $\begin{array}{l}1.88 \pm \\
1.66\end{array}$ & $1.56 \pm 1.46$ & 0.1902 & $\begin{array}{l}4.39 \pm \\
1.89\end{array}$ & $2.74 \pm 1.40$ & $\begin{array}{l}<.0001 * \star \star \star\end{array}$ & $\begin{array}{l}3.12 \pm \\
2.17\end{array}$ & $2.14 \pm 1.54$ & 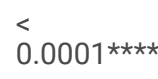 \\
\hline ASDAS & $\begin{array}{l}1.43 \pm \\
0.90\end{array}$ & $1.02 \pm 0.09$ & $0.0007 * \star \star$ & $\begin{array}{l}2.33 \pm \\
0.74\end{array}$ & $1.59 \pm 0.80$ & $\hat{0}_{0.0001^{\star \star * *}}$ & $\begin{array}{l}1.87 \pm \\
0.94\end{array}$ & $1.30 \pm 0.79$ & $<.0001^{\star * \star * *}$ \\
\hline HAQ & $\begin{array}{l}1.87 \pm \\
1.33\end{array}$ & $0.86 \pm 0.88$ & $0.0001 * \star \star \star *$ & $\begin{array}{l}2.27 \pm \\
1.47\end{array}$ & $1.51 \pm 1.13$ & $<.0001^{\star * \star \star *}$ & $\begin{array}{l}2.07 \pm \\
1.40\end{array}$ & $1.18 \pm 1.05$ & $<.0001^{\star * * * \star}$ \\
\hline HAD-An & $\begin{array}{l}4.43 \pm \\
3.32\end{array}$ & $2.87 \pm 2.89$ & $0.0009 * \star \star$ & $\begin{array}{l}6.74 \pm \\
2.97\end{array}$ & $4.80 \pm 3.02$ & $0.0004^{\star \star \star \star}$ & $\begin{array}{l}5.57 \pm \\
3.33\end{array}$ & $3.82 \pm 3.09$ & $\begin{array}{l}<.0001 * \star \star \star \\
0.0\end{array}$ \\
\hline HAD-D & $\begin{array}{l}6.00 \pm \\
3.44\end{array}$ & $4.00 \pm 2.79$ & 0.0016 ** & $\begin{array}{l}7.19 \pm \\
3.26\end{array}$ & $4.74 \pm 3.01$ & $\hat{0}_{0.0001^{\star * \star *}}$ & $\begin{array}{l}5.73 \pm \\
7.43\end{array}$ & $3.63 \pm 5.09$ & $<.0001^{\star * * *}$ \\
\hline $\begin{array}{l}\text { BASDAl- } \\
\text { fatigue }\end{array}$ & $\begin{array}{l}2.57 \pm \\
2.49\end{array}$ & $1.79 \pm 1.84$ & $0.0316^{*}$ & $\begin{array}{l}3.77 \pm \\
5.43\end{array}$ & $2.87 \pm 4.51$ & $0.0143^{*}$ & $\begin{array}{l}2.92 \pm \\
4.22\end{array}$ & $2.16 \pm 3.29$ & 0.001 ** \\
\hline
\end{tabular}

Note: Data are expressed as the mean \pm standard deviation (SD); P-value represents comparison before and after drug administration, $\star \star \star ~ P<0.001$, $\star \star \star P<0.001, * \star P<0.01, * P<0.05$

PDQ=Pain Detection Questionnaire; LBP=Low back pain; CRP=C-reactive protein; ASDAS-CRP=Ankylosing Spondylitis disease activity score-CRP; BASDAl=Bath assessment of ankylosing spondylitis disease activity index; HAQ=Health assessment questionnaire; HAD-An=Hospital Anxiety and Depression Scale -Anxiety; HAD-D=Hospital Anxiety and Depression Scale-Depression

Table 4. Changes of neurotransmitter concentrations in peripheral blood of 20 AS patients and 10healthycontrols

\begin{tabular}{|c|c|c|c|c|}
\hline & $P D Q>19(n=6)$ & $P D Q \leq 12(n=14)$ & Control $(n=10)$ & $\mathrm{P}$ \\
\hline NE & $0.21 \pm 0.06$ & $0.13 \pm 0.05$ & $0.07 \pm 0.02$ & $\nabla 0.001^{\star * \star \star *}$ \\
\hline $5 \mathrm{HT}$ & $22.62 \pm 9.65$ & $20.50 \pm 17.85$ & $19.96 \pm 10.01$ & 0.9338 \\
\hline Gly & $110.8 \pm 21.37$ & $96.61 \pm 25.24$ & $95.32 \pm 34.52$ & 0.5223 \\
\hline Glu & $16.64 \pm 7.32$ & $29.83 \pm 29.05$ & $19.66 \pm 5.05$ & 0.3277 \\
\hline GABA & $587.7 \pm 19.01$ & $629.0 \pm 336.0$ & $523.4 \pm 135.4$ & 0.6213 \\
\hline 5HIAA & $2.21 \pm 0.97$ & $3.97 \pm 3.87$ & $2.62 \pm 0.67$ & 0.3277 \\
\hline KYN & $78.35 \pm 25.35$ & $83.87 \pm 44.80$ & $69.79 \pm 18.05$ & 0.4845 \\
\hline TRP & $1,860 \pm 402.7$ & $2,067 \pm 482.0$ & $2,008 \pm 446.7$ & 0.6528 \\
\hline
\end{tabular}

Note: Data are expressed as the mean \pm standard deviation (SD); $P$-value represents comparison between the three groups, $* \star \star P<0.001, * \star P<0.01$, $\star P<0.05$

$\mathrm{NE}=$ norepinephrine; $5 \mathrm{HT}=$ serotonin; Gly= glycine; Glu=glutamic acid; GABA= $\gamma$-aminobutyric acid; $5 \mathrm{HIAA}=5$-hydroxyindoleacetic acid; $\mathrm{KYN}=$ kynurenine; TRP=tryptophan 


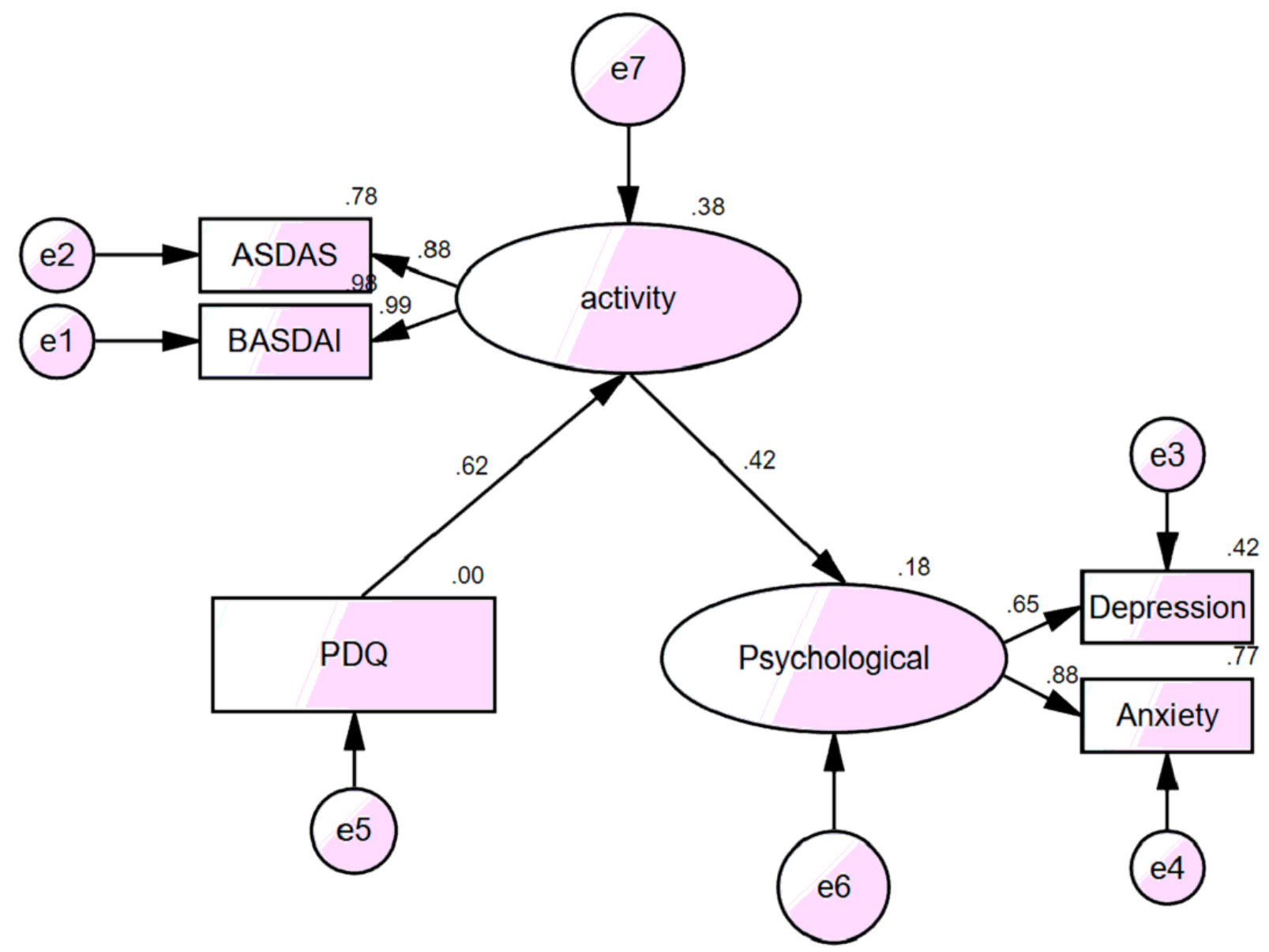

Figure 1

Structural equation modeling Structural equation modeling (SEM) on the impact of neuropathic pain on disease activity and psychology. BASDAI and ASDAS-CRP were used as the disease activity index, and HAD-A and HAD-D were used as the psychological index. SEM was successfully established (probability level $=0.227 ; \mathrm{CMIN} / \mathrm{DF}=1.413 ; \mathrm{CFI}=0.996 ; \mathrm{NFI}=0.987$; and RMSEA $=0.048$ ). According to SEM, PDQ could alter the disease activity $(\beta=0.62, P<0.001)$, and the disease activity could influence the psychological status $(\beta=0.42, P<0.001)$. 